\title{
A associação do enxerto de tecido conjuntivo subepitelial e a matriz derivada do esmalte no recobrimento das recessões gengivais
}

The association of subepithelial connective tissue graft and enamel-derived matrix in the covering of gingival recessions

La asociación de injerto de tejido conectivo subepitelial y matriz deridada dele malte em el recobrimento de recessiones gingivales

\section{Resumo}

A recessão gengival (RG) pode ser definida como uma condição, na qual ocorre a migração em sentido apical com consequente exposição da junção amelo-cementária e superfície radicular. As técnicas cirúrgicas plásticas periodontais objetivam a melhora do fenótipo gengival e a correção da morfologia, posição e dimensões do tecido gengival. Nos últimos anos, com o intuito de melhorar os resultados destes tratamentos, novos recursos relacionados com a otimização da regeneração periodontal, vem sendo associados aos enxertos gengivais. Sendo um coadjuvante ou não às técnicas cirúrgicas de recobrimento radicular, a matriz derivada do esmalte (Emdogain $®$ ), tem sido cada vez mais incorporada nesses tratamentos, na medida em que, tanto sua aplicabilidade clínica, como seus benefícios, já se encontra embasados em evidências científicas. O objetivo deste estudo é realizar uma revisão literária integrativa sobre a utilização da matriz derivada do esmalte (EMD) nos procedimentos cirúrgicos plásticos periodontais para o tratamento da recessão gengival. Para a elaboração do estudo foi utilizada a estratégia PICO e a busca nas bases de dados PubMed, MedLine e Scielo, a partir das seguintes palavras-chave: "enamel matrix derivatives", "gingival retraction" e "subepithelial connective tissue graft". A partir dessa busca 181 artigos publicados entre os anos de 2016 a 2021 foram selecionados, sendo que desse número, somente 12 foram utilizados para realizar a revisão da literatura. Com esta revisão foi possível concluir que a EMD associada aos enxertos de tecido conjuntivo subepitelial pode aumentar a previsibilidade da terapia de recobrimento, podendo favorecer uma nova inserção periodontal.

Palavras-chave: Matriz derivada do esmalte; Retração gengival; Enxerto de tecido conjuntivo subepitelial. 


\begin{abstract}
Gingival recession (GR) can be defined as a condition in which migration occurs in the apical direction with consequent exposure of the cementoenamel junction and root surface. Periodontal plastic surgical techniques aim to improve the gingival phenotype and correct the morphology, position and dimensions of the gingival tissue. In recent years, in order to improve the results of these treatments, new resources related to the optimization of periodontal regeneration have been associated with gingival grafts. Whether or not it is an adjunct to surgical techniques for root coverage, the enamel-derived matrix (Emdogain $(\AA)$ ) has been increasingly incorporated into these treatments, as both its clinical applicability and its benefits are already supported. in scientific evidence. The aim of this study is to carry out an integrative literature review on the use of enamel-derived matrix (EMD) in periodontal plastic surgical procedures for the treatment of gingival recession. For the elaboration of the study, the PICO strategy and the search in the PubMed, MedLine and Scielo databases were used, using the following keywords: "enamel matrix derivatives", "gingival retraction" and "subepithelial connective tissue graft". From this search, 181 articles published between the years 2016 to 2021 were selected, and of this number, only 12 were used to perform the literature review. With this review, it was possible to conclude that EMD associated with subepithelial connective tissue grafts can increase the predictability of the covering therapy, which may favor a new periodontal insertion.
\end{abstract}

Keywords: Enamel matrix derivatives; Gingival retraction; Subepithelial connective tissue graft.

\title{
Resumen
}

La recesión gingival $(\mathrm{RG})$ se puede definir como una condición en la que la migración ocurre en la dirección apical con la consiguiente exposición de la unión amelocementaria y la superficie radicular. Las técnicas de cirugía plástica periodontal tienen como objetivo mejorar el fenotipo gingival y corregir la morfología, posición y dimensiones del tejido gingival. En los últimos años, con el fin de mejorar los resultados de estos tratamientos, se han asociado nuevos recursos relacionados con la optimización de la regeneración periodontal a los injertos gingivales. Sea o no un complemento de las técnicas quirúrgicas para la cobertura radicular, la matriz derivada del esmalte (Emdogain $\left.{ }^{\circledR}\right)$ se ha incorporado cada vez más a estos tratamientos, ya que tanto su aplicabilidad clínica como sus beneficios ya están respaldados por la evidencia científica. El objetivo de este estudio es realizar una revisión integradora de la literatura sobre el uso de la matriz derivada del esmalte (DME) en procedimientos de cirugía plástica periodontal para el tratamiento de la recesión gingival. Para la elaboración del estudio se utilizó la estrategia PICO y la búsqueda en las bases de datos PubMed, MedLine y Scielo, utilizando las siguientes palabras clave: "derivados de la matriz del esmalte", "retracción gingival" e "injerto de tejido conectivo subepitelial". De esta búsqueda se seleccionaron 181 artículos publicados entre los años 2016 a 2021, y de este número, solo 12 se utilizaron para realizar la revisión de la literatura. Con esta revisión se pudo concluir que la EMD asociada a injertos de tejido conectivo subepitelial puede incrementar la predictibilidad de la terapia de cobertura, lo que puede favorecer una nueva inserción periodontal.

Palabras clave: Derivados de la matriz del esmalte; Retracción gingival; Injerto de tejido conectivo subepitelial.

\section{Introdução}

A recessão gengival $(\mathrm{RG})$, pode ser definida como uma condição, na qual ocorre a migração em sentido apical do tecido gengival, consequentemente expondo a junção cemento-esmalte (Seong, 2018). Ela pode ser localizada, em um dente, ou generalizada, em um grupo de dentes. Os fatores etiológicos são diversos dentre eles destacam-se: trauma mecânico durante a escovação, problemas oclusais, acúmulo de placa, ortodontia, etc (Tabassum S, 2017). Vale ressaltar que em pacientes com um fenótipo gengival fino, ou seja, um tecido gengival mais delicado haverá maior probabilidade de ocorrência das recessões (Baker, 2019). Além disso, a recessão gengival acarreta efeitos esteticamente desfavoráveis e dificulta o controle do biofilme no local, o que pode implicar em uma maior susceptibilidade à cárie radicular e também à hipersensibilidade dentinária (Salhi, et al., 2014).

A previsibilidade da terapia de recobrimento radicular está diretamente relacionada com o correto diagnóstico da etiologia da recessão gengival, sendo assim possível classificar corretamente o grau da recessão e consequentemente estruturar planos de tratamentos com os melhores prognósticos (Wyganowska-Swiatkowska, 2017).

Os objetivos dos procedimentos de cirurgia plástica periodontal de cobertura radicular são melhorar as condições estéticas dos pacientes e outros resultados clínicos (por exemplo, nível de inserção clínica e largura do tecido queratinizado) por meio da cobertura de superfícies radiculares previamente desnudadas (Chambrone, et al., 2018). Esses procedimentos propõem-se reparar anormalidades na morfologia, posição e dimensões do tecido gengival (Graziani, 2014; Cairo, 2014). Dessa forma, o objetivo final é a cobertura da superfície radicular exposta, podendo esta estar associada a questões estéticas e 
ou dor decorrente da hipersensibilidade dentinária. As técnicas cirúrgicas de recobrimento radícular utilizando-se enxertos gengivais estão muito bem fundamentadas na literatura, sendo que enxerto de tecido conjuntivo subepitelial (sCTG) é um tratamento que apresenta excelentes prognósticos (Zucchelli, et al., 2005).

Nos últimos anos, com o intuito de melhorar os resultados destes tratamentos, novos recursos relacionados com a otimização da regeneração periodontal vem sendo associados aos enxertos. Como coadjuvante ou não as técnicas cirúrgicas de recobrimento, a proteína da matriz de esmalte (Emdogain ${ }^{\circledR}$ ) vem se mostrando eficaz na melhora dos resultados dos tratamentos. Este biomaterial pode estimular a proliferação de células endoteliais microvasculares e a quimiotaxia, proporcionando uma melhor cicatrização de feridas e remodelação do tecido periodontal (Schlueter, et al., 2007).

Existem diversos estudos sugerindo seu potencial de regeneração, incluindo, osteogênese, dentinogênese e cementogênese (Klewin-Steinböck, S, et al., 2021) (Lyngstadaas, et al., 2009).

O objetivo deste estudo é realizar uma revisão literária integrativa sobre a utilização da matriz derivada do esmalte (EMD), em procedimentos cirúrgicos plásticos periodontais utilizados no tratamento cirúrgico da recessão gengival. O uso deste biomaterial associado à técnica de enxerto de tecido conjuntivo subepitelial (sCTG), vem se tornado rotina nas cirurgias de recobrimento radicular, sendo inclusive relacionado ao aumento da regeneração periodontal e um melhor prognóstico do tratamento.

\section{Metodologia}

Este estudo consta de uma revisão integrativa, com finalidade básica estratégica; forma de abordagem qualitativa e objetivo exploratório descritivo (Estrela, 2018).

Para a elaboração do estudo, foi utilizada a estratégia PICO, para qual se atribuiu em "P” (população/problema saúde): a recessão gengival em adultos, em "I" (intervenção): a associação do sCTG com a EMD, em C (comparação/controle): o retalho avançado coronariamente e em "O" (desfecho): a eficácia da associação do biomaterial (EMD) com o sCTG.

A pergunta utilizada para conduzir o estudo foi: A associação do SCTG com a EMD no tratamento cirúrgico da recessão gengival, aumenta a previsibilidade da terapia de recobrimento radicular?

\subsection{Métodos de busca}

O presente estudo realizou o levantamento de informações por meio de busca na Internet, onde foram consultadas as seguintes bases de dados: PubMed, MedLine e Scielo, com artigos publicados entre os anos de 2016 à 2021. Procedeu-se uma busca, utilizando os seguintes termos chaves: "enamel matrix derivatives", "gingival retraction", "subepithelial connective tissue graft", e operador booleano AND.

\subsection{Critérios de inclusão e exclusão}

Nos critérios de inclusão: (i) artigos que abordem sobre o tema do uso EMD e o sCTG no tratamento das recessões gengivais; (ii) artigos da língua inglesa; (iii) artigos publicados entre os anos 2016 à 2021.

Nos critérios de exclusão: (i) artigos que fugiam do tema abordado, por exemplo, uso da EMD em defeitos ósseos, áreas perimplantares e associados a tratamentos endodônticos, (ii) artigos que não eram da língua inglesa; (iii) estudos com experimentos em animais e relatos de caso. 


\section{Resultados}

A busca feita no banco de dados, sendo PubMed e MedLine e Scielo com as seguintes palavras-chave: "enamel matrix derivatives", "gingival retraction", "subepithelial connective tissue graft" resultou em 181 artigos iminentemente elegíveis. Ao fim, excluindo os artigos sem relação com o tema e de acordo com os filtros utilizados, chegou-se em 12 artigos selecionados e utilizados na íntegra, para realizar a revisão qualitativa.

Figura 1 - Fluxograma utilizado para processo de seleção dos artigos.

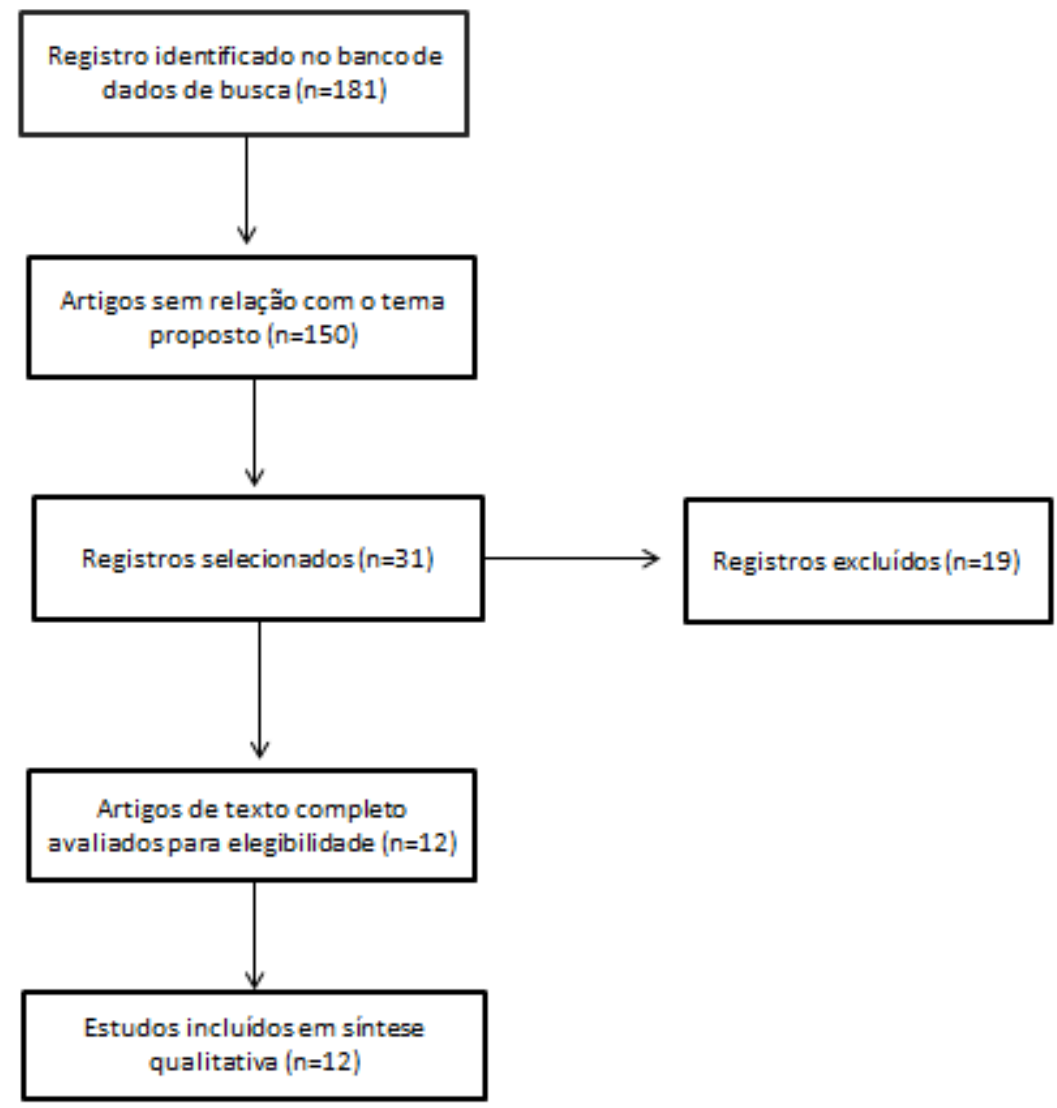

Fonte: Autores.

Quadro 1 - Artigos selecionados para análise qualitativa, descritos por autor, ano de publicação, periódico, objetivos, metodologia, resultados e fator de impacto. Elaborado pelos próprios autores.

\begin{tabular}{|c|c|c|c|c|}
\hline Autor, Ano & $\begin{array}{l}\text { Periódico e fator } \\
\text { de impacto }\end{array}$ & Objetivo & Metodologia & Resultado \\
\hline $\begin{array}{l}\text { Sculean A et } \\
\text { al., } 2018 .\end{array}$ & $\begin{array}{c}\text { Quintessence } \\
\text { International } \\
\text { Periodontology } \\
1.46\end{array}$ & $\begin{array}{l}\text { Avaliar clinicamente a cicatrização de } \\
\text { múltiplas recessões gengivais maxilares } \\
\text { adjacentes de Miller classe I, II, III } \\
\text { (MAGR) tratadas com a técnica de túnel } \\
\text { avançado coronariamente modificado } \\
\text { em conjunto com EMD e sCTG. }\end{array}$ & $\begin{array}{c}\text { Estudo clínico } \\
\text { randomizado }\end{array}$ & $\begin{array}{l}\text { Diante da técnica proposta, o } \\
\text { tratamento de MAGR resulta } \\
\text { em cobertura previsível. }\end{array}$ \\
\hline $\begin{array}{c}\text { Sculean A et } \\
\text { al., } 2018 .\end{array}$ & $\begin{array}{l}\text { The } \\
\text { International } \\
\text { Journal od } \\
\text { Periodontics e } \\
\text { Restorative } \\
\text { Dentstry } \\
1.840\end{array}$ & $\begin{array}{l}\text { Apresentar o procedimento e os } \\
\text { resultados obtidos em uma série de } 24 \\
\text { pacientes tratados por meio de uma } \\
\text { nova técnica cirúrgica LCT (túnel } \\
\text { fechado lateralmente) e utilizando o } \\
\text { sCTG e EMD em recessões de Miller } \\
\text { classes I, II, III isoladas profundas } \\
\text { mandibulares. }\end{array}$ & $\begin{array}{c}\text { Estudo clínico } \\
\text { randomizado }\end{array}$ & $\begin{array}{l}\text { A LCT associado ao sCTG e } \\
\text { EMD representa uma } \\
\text { abordagem previsível para o } \\
\text { tratamento recessão gengival } \\
\text { mandibulares classe I, II e III } \\
\text { de Miller. }\end{array}$ \\
\hline
\end{tabular}




\begin{tabular}{|c|c|c|c|c|}
\hline $\begin{array}{l}\text { Stähli A et } \\
\text { al., } 2019 .\end{array}$ & $\begin{array}{l}\text { Clinical Oral } \\
\text { Investigations } \\
\mathbf{3 . 5 7 3}\end{array}$ & $\begin{array}{l}\text { Investigar clínico e imunológicamente } \\
\text { os efeitos potenciais da EMD na } \\
\text { cicatrização precoce de feridas e os } \\
\text { resultados clínicos após o tratamento } \\
\text { das recessões gengivais únicas e } \\
\text { múltiplas pela técnica de túnel } \\
\text { modificada coronariamente }\end{array}$ & $\begin{array}{l}\text { Ensaio clínico } \\
\text { randomizado, } \\
\text { controlado e } \\
\text { cego único }\end{array}$ & $\begin{array}{l}\text { Não demonstrou influencia da } \\
\text { EMD nos parâmetros clínicos } \\
\text { e imunológicos, relacionados à } \\
\text { cicatrização de feridas após } \\
\text { cirurgia de cobertura de } \\
\text { recessão usando MCAT e } \\
\text { sCTG. }\end{array}$ \\
\hline $\begin{array}{l}\text { Mercado F } \\
\text { et al., } 2019 .\end{array}$ & $\begin{array}{l}\text { Journal of } \\
\text { Periodontal } \\
\text { Research } \\
4.419\end{array}$ & $\begin{array}{l}\text { Comparar os resultados clínicos do } \\
\text { enxerto de tecido conjuntivo } \\
\text { subepitelial (CTG) com e sem EMD no } \\
\text { tratamento de defeitos de recessão } \\
\text { periodontal em Classe I-II de Miller. }\end{array}$ & $\begin{array}{l}\text { Estudo clínico } \\
\text { prospectivo }\end{array}$ & $\begin{array}{l}\text { O uso da EMD como } \\
\text { coadjuvante do CTG, } \\
\text { contribui no tratamento da } \\
\text { recessão gengival, pois foi } \\
\text { capaz de atingir uma margem } \\
\text { gengival mais estável, alterar a } \\
\text { quantidade de tecido } \\
\text { queretinizado, aumentando-o e } \\
\text { reduzir a dor pós-operatória. }\end{array}$ \\
\hline $\begin{array}{l}\text { Mercado F } \\
\text { et al., } 2019 .\end{array}$ & $\begin{array}{c}\text { Journal of } \\
\text { Periodontal } \\
\text { Research } \\
4.419\end{array}$ & $\begin{array}{l}\text { Comparar os resultados clínicos do } \\
\text { CTG com e sem EMD no tratamento de } \\
\text { defeitos de recessão periodontal em } \\
\text { Classe III-IV de Miller. }\end{array}$ & $\begin{array}{l}\text { Estudo clínico } \\
\text { randomizado de } \\
3 \text { anos }\end{array}$ & $\begin{array}{l}\text { A EMD associada ao CTG no } \\
\text { tratamento da recessão } \\
\text { gengival dos dentes anteriores } \\
\text { inferiores de classe III/IV } \\
\text { resulta em melhores resultados } \\
\text { de cobertura radicular, } \\
\text { maiores quantidades de } \\
\text { largura de tecido } \\
\text { queratinizado após } 36 \text { meses } \\
\text { do tratamento e redução da } \\
\text { dor após } 14 \text { dias da cirurgia. }\end{array}$ \\
\hline $\begin{array}{c}\text { Alexiou A et } \\
\text { al., } 2019 .\end{array}$ & $\begin{array}{c}\text { Quintessence } \\
\text { International } \\
\text { Periodontology } \\
\mathbf{1 . 4 6}\end{array}$ & $\begin{array}{l}\text { Comparar a eficiência clínica do EMD } \\
\text { colocado sob um retalho avançado } \\
\text { coronariamente (CAF; grupo teste), com } \\
\text { um enxerto de tecido conjuntivo } \\
\text { colocado sob um CAF (grupo controle), } \\
\text { em pacientes com múltiplos defeitos de } \\
\text { recessão. }\end{array}$ & $\begin{array}{l}\text { Estudo clínico } \\
\text { randomizado } \\
\text { controlado }\end{array}$ & $\begin{array}{l}\text { O uso da EMD pode levar a } \\
\text { resultados clínicos } \\
\text { semelhantes ao uso do sCTG } \\
\text { associado com CAF. }\end{array}$ \\
\hline $\begin{array}{l}\text { Aydinyurt } \\
\text { HS et al., } \\
2019 .\end{array}$ & $\begin{array}{c}\text { Original } \\
\text { Research } \\
\text { Periodontia } \\
4.419\end{array}$ & $\begin{array}{l}\text { Avaliar os impactos clínicos e estéticos } \\
\text { da aplicação da EMD em combinação } \\
\text { com sCTG + CAF em pacientes com } \\
\text { recessões gengivais classe I e II de } \\
\text { Miller em caninos contralaterais da } \\
\text { maxila. }\end{array}$ & $\begin{array}{l}\text { Estudo } \\
\text { controlado } \\
\text { randomizado }\end{array}$ & $\begin{array}{l}\text { O uso adjunto da EMD com } \\
\text { sCTG mostrou afetar os } \\
\text { escores estéticos e as } \\
\text { medições } \\
\text { beneficamente, porém essa } \\
\text { contribuição nánicas } \\
\text { considerada estatisticamente } \\
\text { significativa para todos } \\
\text { parâmetros. }\end{array}$ \\
\hline $\begin{array}{l}\text { Discepolli N } \\
\text { et al., } 2019 .\end{array}$ & $\begin{array}{l}\text { MDPI } \\
4.699\end{array}$ & $\begin{array}{l}\text { Revisar sistematicamente as evidências } \\
\text { que avaliam o benefício adjuvante dos } \\
\text { EMD aplicados com procedimento } \\
\text { periodontal em termos de ganho de } \\
\text { tecido queratinizado em torno da } \\
\text { recessão gengival. }\end{array}$ & $\begin{array}{l}\text { Revisão } \\
\text { sistemática e } \\
\text { meta-análise }\end{array}$ & $\begin{array}{l}\text { O uso da EMD não parece } \\
\text { agregar benefício clínico em } \\
\text { termos de ganho de tecido } \\
\text { queratinizado, independente } \\
\text { da técnica cirúrgica aplicada. }\end{array}$ \\
\hline $\begin{array}{c}\text { Górski B et } \\
\text { al., } 2020 .\end{array}$ & $\begin{array}{l}\text { Clinical Oral } \\
\text { Investigations } \\
\mathbf{3 . 5 7 3}\end{array}$ & $\begin{array}{l}\text { Comparar os resultados da técnica } \\
\text { modificada de túnel avançado } \\
\text { coronáriamente, adjunto com sCTG } \\
\text { com ou sem EMD no tratamento das } \\
\text { recessões gengivais classe } 1 \text { e II de } \\
\text { Miller }\end{array}$ & $\begin{array}{l}\text { Estudo clínico } \\
\text { randomizado }\end{array}$ & $\begin{array}{l}\text { A técnida de túnel modificada } \\
\text { avançada coronariamente com } \\
\text { sCTG foi muito eficaz no } \\
\text { tratamento de múltiplos } \\
\text { defeitos de RT1 e RT2, e a } \\
\text { cobertura radicular e as } \\
\text { medidas dos parâmetros } \\
\text { periodontais não forma } \\
\text { melhorados pelo uso } \\
\text { coadjuvante da EMD. Porém a }\end{array}$ \\
\hline
\end{tabular}




\begin{tabular}{|c|c|c|c|c|}
\hline & & & & $\begin{array}{l}\text { dor pós-operatória precoce foi } \\
\text { reduzida em locais tratados } \\
\text { com EMD e o uso dela, } \\
\text { melhorou os } \begin{array}{l}\text { resultados } \\
\text { estéticos }\end{array} \\
\text { profissionalmente, } 6 \text { meses } \\
\text { após a cirurgia. }\end{array}$ \\
\hline $\begin{array}{c}\text { Górski B et } \\
\text { al., } 2021 \text {. }\end{array}$ & $\begin{array}{l}\text { Clinical Oral } \\
\text { Investigations } \\
\mathbf{3 . 5 7 3}\end{array}$ & $\begin{array}{l}\text { Investigar os fatores que influenciam os } \\
\text { resultados de } 12 \text { meses após o } \\
\text { tratamento de múltiplas recessões } \\
\text { gengivais (GR) com túnel modificado } \\
\text { coronariamente avançado (MCAT) e } \\
\text { enxerto de tecido conjuntivo } \\
\text { subepitelial (SCTG) com derivado de } \\
\text { matriz de esmalte (EMD) (testes) ou } \\
\text { sem (controles). }\end{array}$ & $\begin{array}{c}\text { Estudo clínico } \\
\text { randomizado }\end{array}$ & $\begin{array}{l}\text { Com o uso EMD, melhorou a } \\
\text { cobertura radicular média de } \\
12 \text { meses (ACR), cobertura } \\
\text { total da raiz (CRC) e a } \\
\text { cobertura estética da raiz } \\
\text { (RES) no pós-operatório. A } \\
\text { área de base da superfície } \\
\text { radicular exposta avascular } \\
\text { basal previu ganho de ACR, } \\
\text { CRC e ganho na espessura } \\
\text { gengival (GT) em } 12 \text { meses, } \\
\text { enquanto a GT basal } \\
\text { determinou obtenção de CRC } \\
\text { e RES perfeito. }\end{array}$ \\
\hline $\begin{array}{l}\text { Maurício JM } \\
\text { et al., } 2021 .\end{array}$ & $\begin{array}{c}\text { Clin Oral } \\
\text { Investigations } \\
\mathbf{3 . 5 7 3}\end{array}$ & $\begin{array}{l}\text { Avaliar se aplicação de derivados da } \\
\text { matriz de esmalte fornece benefícios } \\
\text { clínicos adicionais no tratamento da } \\
\text { recessão gengival miller maxilar classe I } \\
\text { e II. }\end{array}$ & $\begin{array}{l}\text { Revisão } \\
\text { sistemática e } \\
\text { meta-análise }\end{array}$ & $\begin{array}{l}\text { O uso da EMD associado com } \\
\text { CAf ou CTG no tratamento da } \\
\text { recessão gengival teve } \\
\text { redução da recessão e ganho } \\
\text { de CAL em } 6 \text { e } 12 \text { meses, } \\
\text { porém o efeito da EMD no } \\
\text { ganho de tecido queratinizado } \\
\text { se mostrou muito baixo. }\end{array}$ \\
\hline $\begin{array}{l}\text { Zuhr O et } \\
\text { al., } 2021 .\end{array}$ & $\begin{array}{c}\text { Journal od } \\
\text { Clinical } \\
\text { Periodontology } \\
\mathbf{8 , 7 2 8}\end{array}$ & $\begin{array}{l}\text { Comparar a eficácia clínica da técnica } \\
\text { de túnel com sCTG versus CAF com } \\
\text { EMD } 5 \text { anos após a terapia da recessão } \\
\text { gengival. }\end{array}$ & $\begin{array}{l}\text { Estudo clínico } \\
\text { randomizado }\end{array}$ & $\begin{array}{l}\text { O sCTG resultou em melhores } \\
\text { resultados clínicos e estéticos } \\
\text { do que CAF + EMD. }\end{array}$ \\
\hline
\end{tabular}

Fonte: Autores.

\section{Discussão}

As recessões gengivais apresentam uma elevada prevalência na população adulta (Seong, 2018). Estudos sugerem que existe um grupo de dentes específico que é mais afetado por essa condição: incisivos inferiores, molares superiores e inferiores e pré-molares, sendo estes últimos os mais afetados (Graziani, 2019). Diante de uma condição tão prevalente, a busca por protocolos cirúrgicos periodontais mais previsíveis e que sejam capazes de garantir uma melhor estabilidade dos tecidos periodontais, bem como um bom prognóstico em longo prazo, fez com que novas estratégias presentes no ramo da engenharia tecidual sejam incluídas às terapias convencionais de recobrimento radicular (Mercado, et al., 2019).

Várias técnicas cirúrgicas têm se mostrado eficientes no tratamento cirúrgico das recessões gengivais ao longo dos anos como: retalhos posicionados coronariamente, retalhos de deslizamento lateral, retalhos de papila duplos, enxertos gengivais livres, enxerto de tecido conjuntivo subepitelial, regeneração tecidual guiada e aloenxertos (De Sanctis, 2007; Cortellini, 2012), sendo o enxerto de tecido conjuntivo subepitelial (sCTG) considerado "padrão ouro", por apresentar uma alta previsibilidade (Mercado, et al., 2019).

A matriz do esmalte humano e a porcina apresentam alta homogeneidade, com isso, acredita-se que a EMD EMD simule o papel das proteínas da matriz do esmalte na cementogênese, após a sua aplicação na superfície radicular desnuda. A EMD promove estímulos bioativos ao microambiente local e também uma nova regeneração periodontal (Suarez-Lopez Del 
Amo F, 2015). Dessa forma, a EMD atua como um complemento ao sCTG no tratamento da recessão gengival, facilitando uma nova inserção periodontal.

O sCTG tem sido mais indicado em pacientes que apresentam um fenótipo gengival fino, mostrando-se assim sua relevância clínica (Aroca S, et al., 2010; Sarfati A, et al., 2010). No tratamento da recessão gengival, a associação da EMD com o sCTG, promoveu uma melhora da cicatrização, sendo que histologicamente houve a formação de ligamento periodontal, osso alveolar e um novo cemento radicular (Miron, 2016; Shirakata, 2018). Com o intuito de melhorar os resultados clínicos desse tratamento, estudos têm demonstrado que o condicionamento da superfície radicular com EDTA, previamente a aplicação da EMD, favoreceu mais o prognóstico dos casos, já que o seu uso contribui para uma descontaminação da superfície radicular (Barootchi, 2018).

Apesar de alguns estudos terem relatado que o uso da EMD associada ao sCTG não apresentarem diferença significativa quando utilizados nos recobrimentos, é sabido que a EMD pode otimizar as etapas iniciais da cicatrização local, além de diminuir as taxas de complicações pós operatórias (Stähli A et al., 2019). Diversos estudos in vitro demonstraram que a EMD estimula o crescimento e o metabolismo celular, a proliferação e migração de células do ligamento periodontal (Gibson, 2008; Haase HR, 2001) e aumenta a taxa de adesão das células do ligamento periodontal.

Alexiou, et al. (2019) avaliou os resultados de 6 meses da eficácia do SCTG sozinho versus EMD com retalho avançado coranariamente (sem enxerto associado) em recessões classe I ou II de Miller maxilares. Os resultados revelaram uma redução significativa da recessão e melhora nível de inserção clínico para ambos os grupos. Conforme já discutido anteriormente, e devido ao tempo de somente seis meses de avaliação, sugere-se que realmente nesse tempo o uso somente da sCTG se mantém estável, porém, talvez em um prazo mais longo, conforme já discutido, sCTG sozinho não apresenta a mesma previsibilidade.

Pesquisas clínicas enfatizando o bom prognóstico da associação de EMD e sCTG no recobrimento radicular também já vêm sendo descritas (Hegewald, et al., 2002 e Spahr, et al., 2005), destacando o bom prognóstico da técnica combinada e demonstrando histologicamente que realmente há a presença de uma margem gengival mais estável, a formação de novo osso, novo cemento e também de novas fibras de inserção na superfície do dente (McGuire, et al., 2016 e Sculean, et al., 2000), A maior previsildidade a longo prazo dos tratamentos com essa associação. MERCADO, 2019 demonstraram que tanto o sCTG associado com a EMD, quanto o sCTG de forma isolada foram altamente eficazes no recobrimento radicular, o qual se permaneceu estável por 24 meses de acompanhamento. Contudo, após um tempo de 36 meses, houve uma diferença entre os dois grupos, no qual a terapia associada obteve melhores resultados, quando comparados com o de uso isolado de sCTG em termos de cobertura radicular média percentual $(90,69 \% \pm 10,10 \%$ vs $79,25 \% \pm 19,55 \%)$ e níveis de recessão residuais $(0,39 \pm$ 0,19 vs $0,92 \pm 0,43 \mathrm{~mm}$ ), propondo assim, uma cobertura radicular mais estável. Portanto, esses achados corroboram que pode haver efeitos benéficos a longo prazo do uso concomitante da EMD e sCTG no tratamento da recessão gengival de Classe I-II de Miller. Os autores também avaliaram os tratamentos em recessões classe III e IV de Miller e nestes casos, em um prazo de 24 meses, houve instabilidade do posicionamento da nova margem gengival nos pacientes em que foram tratados somente com sCTG. Para os pacientes que foram tratados com a técnica combinada foi possível observar a estabilidade no local do recobrimento e a manutenção do fenótipo gengival. corroborando que, em um prognóstico a longo prazo, o uso dessa técnica é mais eficaz.

Recentemente dois estudos de meta-análise Discepoli, et al., (2019), e Maurício, et al., (2021) concluem que o uso da MDE em conjunto com técnicas bilaminares de recobrimento (deslize coronal e enxerto de tecido conjuntivo) com o intuito de modificar o fenótipo gengival, aumentando espessura de tecido queratinizado parece não ser significativo. Contudo, o fato de que a EMD tem mais efeitos benéficos na estabilidade da nova margem, com ganho de inserção clínica pela presença de novo cemento, parece ser uma forte evidência para o prognóstico dos recobrimentos, conforme já discutimos nesta revisão. 


\section{Conclusão}

Diante do exposto, pode-se concluir que, a EMD associada ao sCTG no tratamento das retrações gengivais trás efeitos benéficos, como: estabilidade da nova margem gengival, correção do fenótipo gengival, estimulação da formação de cemento e ligamento periodontal, redução do nível de inserção e da recessão gengival e promove uma melhora na cicatrização do enxerto gengival.

São imprescindíveis mais estudos seguindo essa linha de pesquisa, devido à recessão gengival ser uma doença prevalente na população mundial. Dessa forma, conhecendo mais sobre os biomateriais e as técnicas cirúrgicas disponíveis, é possível determinar melhores prognósticos no tratamento das recessões gengivais.

\section{Referências}

Alexiou, A., Vouros, I., Menexes, G., \& Konstantinidis, A. (2017). Comparison of enamel matrix derivative (Emdogain) and subepithelial connective tissue graft for root coverage in patients with multiple gingival recession defects: A randomized controlled clinical study. Quintessence international (Berlin, Germany: 1985), 48(5), 381-389.

Aroca, S., Keglevich, T., Nikolidakis, D., Gera, I., Nagy, K., Azzi, R., \& Etienne, D. (2010). Treatment of class III multiple gingival recessions: a randomizedclinical trial. Journal of clinical periodontology, 37(1), 88-97.

Aydinyurt, H. S., Tekin, Y., \& Ertugrul, A. S. (2019). The effect of enamel matrix derivatives on root coverage: a 12-month follow-up of a randomized clinical trial. Brazilian oral research, 33, e006.

Baker P. (2020). Gingival Recession - Causes and Management. Primary dental journal, 8(4), 40-47.

Cairo, F., Nieri, M., \& Pagliaro, U. (2014). Efficacy of periodontal plastic surgery procedures in the treatment of localized facial gingival recessions. A systematic review. Journal of clinical periodontology, 41, S44-S62, 2014.

Chambrone, L., Salinas Ortega, M. A., Sukekava, F., Rotundo, R., Kalemaj, Z., Buti, J., \& Pini Prato, G. P. (2018). Root coverage procedures for treating localised and multiple recession-type defects. The Cochrane database of systematic reviews, 10(10), CD007161.

Cortellini, Pierpaolo; Pini Prato, Giovanpaolo. Cortellini, P., \& Pini Prato, G. (2012). Coronally advanced flap and combination therapy for root coverage. Clinical strategies based on scientific evidence and clinical experience. Periodontology 2000, 59(1), 158-184.

De Sanctis, Massimo; Zucchelli, G. de Sanctis, M., \& Zucchelli, G. (2007). Coronally advanced flap: a modified surgical approach for isolated recession-type defects: three-year results. Journal of clinical periodontology, 34(3), 262-268, 2007.

Discepoli, N., Mirra, R., \& Ferrari, M. (2019). Efficacy of Enamel Derivatives to Improve Keratinized Tissue as Adjunct to Coverage of Gingival Recessions: A Systematic Review and Meta-Analysis. Materials (Basel, Switzerland), 12(17), 2790.

Estrela, C. (2018). Metodologia Científica: Ciência, Ensino, Pesquisa. Editora Artes Médicas.

Gibson CW (2008) A amelogenina “proteínas do esmalte” e células do periodonto. Crit Rev Eukaryot Gene Expr 18 (4): 345-360.

Górski, B., Górska, R., Szerszeń, M., \& Kaczyński, T. (2021). Modified coronally advanced tunnel technique with enamel matrix derivative in addition to subepithelial connective tissue graft compared with connective tissue graft alone for the treatment of multiple gingival recessions: prognostic parameters for clinical treatment outcomes. Clinical oral investigations.

Górski, B., Górska, R., Wysokińska-Miszczuk, J., \& Kaczyński, T. (2020). Tunnel technique with enamel matrix derivative in addition to subepithelial connective tissue graft compared with connective tissue graft alone for the treatment of multiple gingival recessions: a randomized clinical trial. Clinical oral investigations, 24(12), 4475-4486.

Graziani, F., Gennai, S., Roldán, S., Discepoli, N., Buti, J., Madianos, P., \& Herrera, D. (2014). Efficacy of periodontal plastic procedures in the treatment of multiple gingival recessions. Journal of clinical periodontology, 41, S63-S76, 2014.

Haase HR, Bartold PM (2001) O derivado da matriz do esmalte induz a síntese da matriz por células de fibroblastos periodontais humanos em cultura. $J$ Periodontol 72 (3): 341-348.

Hagewald S, Spahr A, Rompola E, et al. Hägewald, S., Spahr, A., Rompola, E., Haller, B., Heijl, L., \& Bernimoulin, J. P. (2002). Comparative study of Emdogain and coronally advanced flap technique in the treatment of human gingival recessions. A prospective controlled clinical study. Journal of clinical periodontology, 29: 35-41.

Lyngstadaas, S. P., Wohlfahrt, J. C., Brookes, S. J., Paine, M. L., Snead, M. L., \& Reseland, J. E. (2009). Enamel matrix proteins; old molecules for new applications. Orthodontics \& craniofacial research, 12(3), 243-253, 2009.

McGuire, M. K., Scheyer, E. T., \& Schupbach, P. (2016). A Prospective, Case-Controlled Study Evaluating the Use of Enamel Matrix Derivative on Human Buccal Recession Defects: A Human Histologic Examination. Journal of periodontology, 87: 645-653

Mercado, F., Hamlet, S., \& Ivanovski, S. (2020). A 3-year prospective clinical and patient-centered trial on subepithelial connective tissue graft with or without enamel matrix derivative in Class I-II Miller recessions. Journal of periodontal research, 55(2), $296-306$. 
Mercado, F., Hamlet, S., \& Ivanovski, S. (2020). Subepithelial connective tissue graft with or without enamel matrix derivative for the treatment of multiple Class III-IV recessions in lower anterior teeth: A 3-year randomized clinical trial. Journal of periodontology, 91(4), $473-483$.

Miron RJ, Sculean A, Cochran DL, Froum S, Zucchelli G, Nemcovsky C, Donos N, Lyngstadaas SP, Deschner J, Dard M, Stavropoulos A, Zhang Y, Trombelli L, Kasaj A, Shirakata Y, Cortellini P, Tonetti M, Rasperini G, Jepsen S, Bosshardt DD (2016) Vinte anos de derivada da matriz do esmalte: o passado, o presente e o futuro. J Clin Periodontol 43 (8): 668-683.

Meza Mauricio, J., Furquim, C. P., Bustillos-Torrez, W., Soto-Peñaloza, D., Peñarrocha-Oltra, D., Retamal-Valdes, B., \& Faveri, M. (2021). Does enamel matrix derivative application provide additional clinical benefits in the treatment of maxillary Miller class I and II gingival recession? A systematic review and meta-analysis. Clinical oral investigations, 25(4), 1613-1626.

Salhi, L., Lecloux, G., Seidel, L., Rompen, E., \& Lambert, F. (2014). Coronally advanced flap versus the pouch technique combined with a connective tissue graft to treat Miller's class I gingival recession: a randomized controlled trial. Journal of clinical periodontology, 41(4), 387-395.

Sarfati, A., Bourgeois, D., Katsahian, S., Mora, F., \& Bouchard, P. (2010). Risk assessment for buccal gingival recession defects in an adult population. Journal of periodontology, 81: 1419-1425.

Schlueter, S. R., Carnes, D. L., \& Cochran, D. L. (2007). In vitro effects of enamel matrix derivative on microvascular cells. Journal of periodontology, v. 78, n. 1, p. 141-151, 2007.

Sculean, A., Chiantella, G. C., Windisch, P., \& Donos, N. (2000). Clinical and histologic evaluation of human intrabony defects treated with an enamel matrix protein derivative (Emdogain). The International journal of periodontics \& restorative dentistry, 20: 374-381.

Sculean, A., \& Allen, E. P. (2018). The Laterally Closed Tunnel for the Treatment of Deep Isolated Mandibular Recessions: Surgical Technique and a Report of 24 Cases. The International journal of periodontics \& restorative dentistry, 38(4), 479-487.

Sculean, A., Cosgarea, R., Stähli, A., Katsaros, C., Arweiler, N. B., Miron, R. J., \& Deppe, H. (2016). Treatment of multiple adjacent maxillary Miller Class I, II, and III gingival recessions with the modified coronally advanced tunnel, enamel matrix derivative, and subepithelial connective tissue graft: A report of 12 cases. Quintessence international (Berlin, Germany: 1985), 47(8), 653-659.

Seong, J., Bartlett, D., Newcombe, R. G., Claydon, N., Hellin, N., \& West, N. X. (2018). Prevalence of gingival recession and study of associated related factors in young UK adults. Journal of dentistry, 76, 58-67.

Spahr, A., Haegewald, S., Tsoulfidou, F., Rompola, E., Heijl, L., Bernimoulin, J. P., Ring, C., Sander, S., \& Haller, B. (2005). Coverage of Miller class I and II recession defects using enamel matrix proteins versus coronally advanced flap technique: a 2-year report. Journal of periodontology, 76(11), 1871-1880.

Stähli, A., Imber, J. C., Raptis, E., Salvi, G. E., Eick, S., \& Sculean, A. (2020). Effect of enamel matrix derivative on wound healing following gingival recession coverage using the modified coronally advanced tunnel and subepithelial connective tissue graft: a randomised, controlled, clinical study. Clinical oral investigations, 24(2), 1043-1051.

Suárez-López Del Amo, F., Monje, A., Padial-Molina, M., Tang, Z., \& Wang, H. L. (2015). Biologic Agents for Periodontal Regeneration and Implant Site Development. BioMed research international, 2015, 957518.

Tabassum, S., Adnan, S., \& Khan, F. R. (2017). Gingival Retraction Methods: A Systematic Review. Journal of prosthodontics: official journal of the American College of Prosthodontists, 26(8), 637-643.

Wyganowska-Swiatkowska, M., Urbaniak, P., Lipinski, D., Szalata, M., Borysiak, K., Jakun, J., \& Kotwicka, M. (2017). Effects of enamel matrix proteins on adherence, proliferation and migration of epithelial cells: A real-time in vitro study. Experimental and therapeutic medicine, 13(1), 160-168.

Zucchelli, G., \& De Sanctis, M. (2005). Long-term outcome following treatment of multiple Miller class I and II recession defects in esthetic areas of the mouth. Journal of periodontology, 76(12), 2286-2292.

Zuhr, O., Akakpo, D., Eickholz, P., Vach, K., Hürzeler, M. B., Petsos, H., \& Research Group for Oral Soft Tissue Biology \& Wound Healing (2021). Tunnel technique with connective tissue graft versus coronally advanced flap with enamel matrix derivate for root coverage: 5-year results of an RCT using 3D digital measurement technology for volumetric comparison of soft tissue changes. Journal of clinical periodontology, 48(7), 949-961. 